\title{
The load/capacity ratio affects the sit-to-stand movement strategy
}

\author{
Citation for published version (APA):
}

Savelberg, H. H. C. M., Fastenau, A., Willems, P. J., \& Meijer, K. (2007). The load/capacity ratio affects the sit-to-stand movement strategy. Clinical Biomechanics, 22(7), 805-812.

https://doi.org/10.1016/j.clinbiomech.2007.05.002

Document status and date:

Published: 01/01/2007

DOI:

10.1016/j.clinbiomech.2007.05.002

Document Version:

Publisher's PDF, also known as Version of record

\section{Document license:}

Taverne

\section{Please check the document version of this publication:}

- A submitted manuscript is the version of the article upon submission and before peer-review. There can be important differences between the submitted version and the official published version of record.

People interested in the research are advised to contact the author for the final version of the publication, or visit the DOI to the publisher's website.

- The final author version and the galley proof are versions of the publication after peer review.

- The final published version features the final layout of the paper including the volume, issue and page numbers.

Link to publication

\footnotetext{
General rights rights.

- You may freely distribute the URL identifying the publication in the public portal. please follow below link for the End User Agreement:

www.umlib.nl/taverne-license

Take down policy

If you believe that this document breaches copyright please contact us at:

repository@maastrichtuniversity.nl

providing details and we will investigate your claim.
}

Copyright and moral rights for the publications made accessible in the public portal are retained by the authors and/or other copyright owners and it is a condition of accessing publications that users recognise and abide by the legal requirements associated with these

- Users may download and print one copy of any publication from the public portal for the purpose of private study or research.

- You may not further distribute the material or use it for any profit-making activity or commercial gain

If the publication is distributed under the terms of Article $25 \mathrm{fa}$ of the Dutch Copyright Act, indicated by the "Taverne" license above, 


\title{
The load/capacity ratio affects the sit-to-stand movement strategy
}

\author{
H.H.C.M. Savelberg *, A. Fastenau, P.J.B. Willems, K. Meijer \\ Department of Human Movement Science, Nutrition and Toxicology Research Institute, Faculty of Health, Medicine and Life Sciences, \\ Universiteit Maastricht, Maastricht, The Netherlands \\ Received 23 February 2007; accepted 3 May 2007
}

\begin{abstract}
Background. In this study the effect of a changed load/capacity ratio on sit-to-stand performance and on the underlying net joint moments was investigated. In subjects with muscle weakness the load/capacity ratio is increased due to reduced muscle capacity. In the current study this ratio was manipulated by changing the load. This approach allowed studying the isolated effect of an increased load/capacity ratio on sit-to-stand strategy.

Methods. Ten healthy women performed sit-to-stand movements under four load conditions. The load/capacity ratio was manipulated by adding $0 \%, 15 \%, 30 \%$ and $45 \%$ of the body mass to a weight vest. To determine changes in sit-to-stand strategy flexion of the trunk and temporal characteristics were assessed. Joint moments at ankle, knee and hip joints and activation patterns of major leg muscles were determined from the kinematics and kinetics.

Findings. Increasing the extra load from $30 \%$ to $45 \%$ changed the sit-to-stand performance. In the $45 \%$ condition maximal trunk flexion was increased and movement time significantly elongated. The strategy change was associated with a disproportionate increase of the net hip extension moment and a delayed peak of the net knee extension moment.

Interpretation. This study shows that experimentally observed changes in sit-to-stand strategy can be attributed to an increase in the load/capacity ratio. For treatment purposes this implies that increasing muscle strength, reducing body mass or a combination of these could be a suitable approach to improve sit-to-stand performance. The experimental model applied will be useful to study the isolated effect of the load/capacity ratio.
\end{abstract}

(C) 2007 Elsevier Ltd. All rights reserved.

Keywords: Net joint moments; Electromyography; Muscle weakness

\section{Introduction}

Rising from a chair is a task performed many times a day. The elderly and people with muscle weakness often experience considerable difficulty in accomplishing this common task. Difficulty in rising from a chair dramatically impairs independent living (Guralnik et al., 1995). Several studies have focused on the (impaired) sit-to-stand (STS) movement and have compared the strategies employed by the elderly to those of younger persons (Alexander et al.,

\footnotetext{
* Corresponding author.

E-mail address: hans.savelberg@bw.unimaas.nl (H.H.C.M. Savelberg).
}

1991; Doorenbosch et al., 1994; Ikeda et al., 1991; Kerr et al., 1997; Moxley Scarborough et al., 1999; Schenkman et al., 1996; Papa and Cappozzo, 2000; Hughes et al., 1994; Schultz et al., 1992). A general conclusion from these studies is that the elderly prefer a different STS-strategy than young adults. The elderly tend to perform the sit-tostand movement with exaggerated trunk flexion before the moment of seat-off. Moreover, this strategy is characterized by elongated total movement time. The strategy adopted by the elderly has been referred to as the stabilization strategy; the normal strategy is called the momentum transfer strategy.

Understanding what the age-related circumstances are that lead to a strategy change, would allow to design 
and optimize intervention programmes. Schultz et al. (1992) among others suggested that postural stability required adaptations in rising strategy. By bringing the body mass over the feet prior to seat-off, the body could remain relatively stable during seat-off. Alternatively, the strategy change has been suggested to be most adequate to compensate for muscle weakness, especially of the knee extensors (Hughes et al., 1996). Numerous studies have investigated the influence of chair-related (e.g. seat height, armrests etc.) and condition-related (e.g. foot position, speed etc.) determinants of STS-performance (see (Janssen et al., 2002) for a review). Although understanding of these factors will certainly be helpful to improve function in daily living, real independence can only be achieved by understanding and improving subject-related determinants (ageing, muscle weakness, reduced sensibility (Eils et al., 2004; Meyer et al., 2004; Nurse and Nigg, 2001), reduced attention, self-confidence (Kaya et al., 1998 ) etc.). Based on cross-sectional studies it has been suggested that muscle weakness is an important factor (Hughes et al., 1996; Bernardi et al., 2004). However, different subject-related factors may covary with age-related muscle strength reduction. Therefore it will be complicated to identify from a cross-sectional study to which extent muscle weakness determines change of STS-strategy (Janssen et al., 2002). Longitudinal intervention studies are cumbersome in applying a standardized intervention programme and with respect to subject compliance. Moreover, with respect to understanding to what extent different subject-related factors contribute to a strategy change in STS, longitudinal intervention studies are confronted with a similar problem as cross sectional studies, namely that it cannot be excluded that besides muscle strength other determinants are affected as well. To understand the contribution of muscle weakness to STS-performance an experimental model will be needed that allows studying the isolated effect of reduced muscle strength.

In people with muscle weakness the load/capacity ratio, i.e. the ratio between the force that is required and the force that can be generated, is negatively affected. A ratio can be changed by either adjusting the numerator or the denominator. In ageing this load/capacity ratio is generally affected by a decreased denominator, i.e. reduced muscle strength or power. Presumably, an increase in the load would lead to a similar adaptation of the load/capacity ratio. Increasing the load, i.e. body mass, provides a relatively easy applicable method to simulate load/capacity ratios that resemble those found in ageing and chronic diseases. Varying the load can be accomplished without affecting other variables, and thus the isolated effect of increasing the load/capacity ratio can be studied.

The aim of this study was to investigate whether an acute manipulation of the load/capacity ratio by increasing the load can induce a strategy change that mimics the STSstrategy as reported in elderly.

\section{Methods}

\subsection{Subjects and experimental protocol}

Ten young, healthy women (age: 18-28 years; body mass: 62.9 (7.4) kg; body mass index (BMI): 22.0 $(1.6) \mathrm{kg} / \mathrm{m}^{2}$ ) participated in this study. Subjects with orthopaedic abnormalities of the legs, the upper or lower back, neurological diseases or a period of severe illness within three weeks prior to the experiments were excluded from participation. Informed consent was obtained from all subjects.

\subsection{Experimental procedures}

Subjects were asked to stand up from a seat that was adjustable in height. This stool had neither a back support nor arm rests. The starting position was standardized for each subject, so that the knee joint was at an angle of $90^{\circ}$ while the feet were flat on the floor. The subject's arms were folded in front of the chest and the trunk was held in a vertical position with a slight kyphosis of the spine. Both feet were placed on the force platform, parallel and about five centimetres apart. The lateral malleolus was positioned behind the knee, which means that the ankle was in dorsal flexion, so that the initial knee angle was set in $90-100^{\circ}$ of flexion (full extension was defined as $0^{\circ}$ ). After a verbal starting sign, the subject had to stand up in a comfortable manner at a self-selected speed. The subjects were asked to rise in a symmetrical way, loading both legs equally, also they were instructed not to displace their feet during the STS-movement.

By means of a load waistcoat four load conditions were applied. Subjects performed the sit-to-stand task with $0 \%$, $15 \%, 30 \%$ and $45 \%$ of their body mass added. The waistcoat allowed an even distribution of the added mass around the trunk. Each condition was performed twice. Different load conditions were performed in random order. Subjects were allowed to practice the added weight conditions, so that unfamiliarity with the added weight of the waistcoat would not be the cause of a strategy change.

\subsection{Measurements}

Kinetic and kinematic data were collected during each trial. A force platform (Kistler type 9281A) was used to determine the magnitude of the vertical and the anteriorposterior component of the ground reaction force as well as the position of its point of application. Using a digital video camera $(50 \mathrm{~Hz})$ sagittal images of reflective markers on the right leg were obtained. The spatial accuracy of the kinematic measurements was $3.85 \mathrm{~mm}$. These markers were placed on the skin at the head of the fifth metatarsal joint, the lateral malleolus, the tuber calcanei, the collateral ligament on the level with the knee joint, the greater trochantor and the lateral and prominent border of the acromion. 
Electromyography (EMG) was applied to measure the activity of the major muscle groups in the lower right extremity. Bipolar skin surface electrodes were place over m. gluteus maximus (GLMX), m. biceps femoris (BF), $m$. rectus femoris $(\mathrm{RF}), m$. vastus medialis $(\mathrm{VM}), m$. gastrocnemius medialis $(\mathrm{GM}), m$. soleus (SOL) and $m$. tibialis anterior (TA). All data (video, EMG and force platform) were synchronised.

\subsection{Data processing}

To determine the timing of the movement, the start and the end of the movement and the instant of seat-off were defined. The start of the movement was defined as the instant at which the first horizontal displacement of the shoulder marker was seen. The first vertical displacement of the hip marker defined seat-off. The movement was considered to be finished when the hip joint angle achieved its maximal value (Fig. 1). The hip joint angle was defined as the angle between the line connecting the acromion marker and the greater trochanter marker and the line connecting the trochanter major marker and the collateral ligament marker.

Raw EMG-data were rectified and filtered (third-order Butterworth filter, $5 \mathrm{~Hz}$ cut off frequency; Fig. 1). Subsequently the maximal values for these processed EMG-data were determined.

Using Winter's model (Winter, 1990) inertial parameters of the foot, lower leg and thigh were calculated based on the subjects body mass and segment lengths. Based on these inertial data, the accelerations of the segments and ground reaction force, the net joint moments (NJM) at ankle, knee and hip joint were calculated using an inverse dynamics approach (cf (Sibella et al., 2003)). By double differentiating the kinematic data obtained by the video analysis, the accelerations of the body segments (foot, lower leg and thigh) were calculated. Both maximal values for the NJMs and the timing of these maxima were determined. Timing was calculated as percentage of the movement time after seat-off. Moreover for each joint moment the relative contribution to the total extending joint moment was calculated. The total extending joint moment was defined as the sum of the maximal ankle plantar flexion, the maximal knee joint extension and the maximal hip joint extension moment.

\subsection{Statistics}

Data of one subject were discarded as she could not finish all measurements correctly. As no effect of the two repetitions that were performed was found, data of these repetitions were averaged. Thus for each dependent variable, 36 values were present ( 9 subjects, 4 conditions). Missing values (four of 36 cases) were replaced by the group average. To detect load-induced changes in movement strategy, data were analysed in SPSS with the General
Linear Model for repeated measurements. A significance level of $P<0.05$ was chosen.

\section{Results}

To assess a strategy change, elongation of the movement time and flexion of trunk are important variables. Increasing the load resulted in a significant increase of the total movement time; in the $45 \%$ added mass condition the movement lasted on the average $22 \%$ longer than in the unloaded condition (Table 1). The time to seat-off was not affected. The minimal hip joint angle decreased when the load was increased $(P<0.001)$. In the $45 \%$ added mass condition the minimal hip joint angle was about $10^{\circ}$ smaller than in the three other conditions (Table 1).

Maximal NJM at all three joints considered, ankle, knee and hip joint, increased significantly $(P=0.001$; Table 1$)$ with increasing load. For the ankle and knee joint a more or less linear increase of NJM with load occurred. For the hip joint the NJM only increased when the added load was $30 \%$ or more of the body mass (Table 1; Fig. 2). Also the contribution of adjacent joints to the total extending NJM shifted significantly with increasing the load; in the more demanding conditions the contribution of the ankle plantar flexion NJM increased, that of the knee extension NJM remained more or less constant and that of the hip extension NJM decreased.

For the knee extension NJM the load affected the timing of the maximal value; in the $0 \%, 15 \%$ and $30 \%$ conditions maximal NJM occurred at approximately $17 \%$ of the movement duration, in the $45 \%$ condition a significant shift to $24 \%$ of the movement was found. For the ankle joint the variation in the timing of the maximal NJM was rather larger; it varied between $62 \%$ and $85 \%$ of the movement cycle. The maximal hip extension NJM occurred invariantly between $11 \%$ and $14 \%$ of the cycle (Table 1 ).

Whereas the activity of the muscles of the upper leg (GLMX, BF, RF, VM and GM) increased with each load increment; that of the three lower leg muscles (SOL and TA) was constant over the load conditions (Table 1). Most muscles showed a gradual increase of activity over the four load conditions. In the BF activity was only increased with the last load step.

\section{Discussion}

This study showed that changing the load/capacity ratio by increasing the load is a good model to evoke the strategy change that is also found in elderly. It was found that when the load was increased the movement time became $22 \%$ longer and the minimal hip joint angle was smaller, indicating that forward flexion was increased by more than $10^{\circ}$. These changes are representative of the stabilization STSstrategy. In the literature comparable values for these characteristics have been reported for elderly (Schultz et al., 1992; Papa and Cappozzo, 2000; Kerr et al., 1997); in these studies changes in muscle capacity have not been 

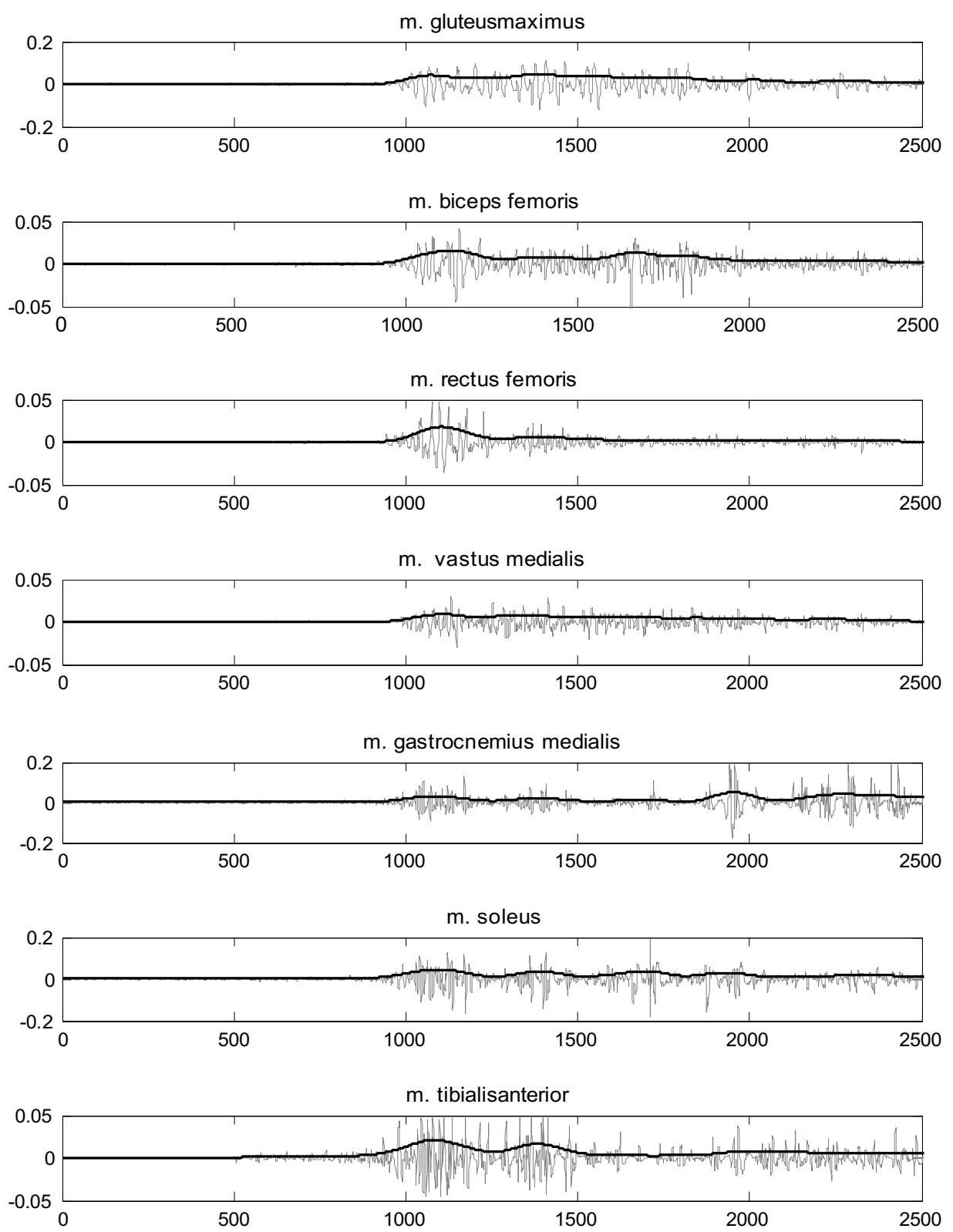

GRF, verticalposition hip marker, hip joint angle

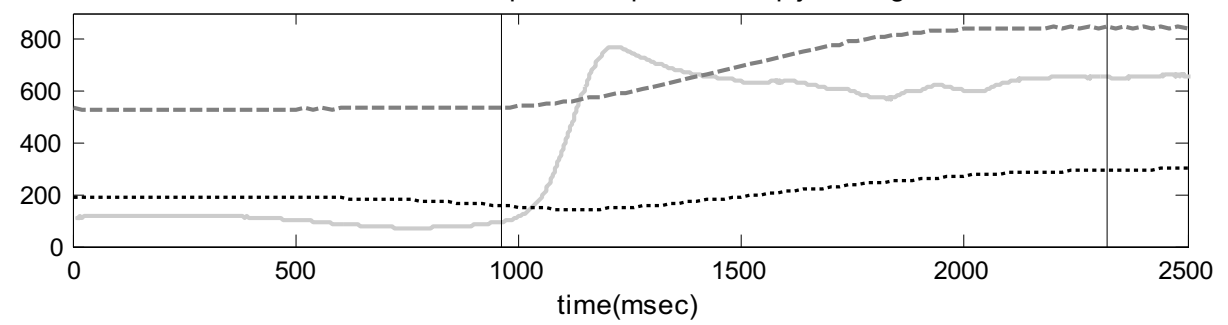

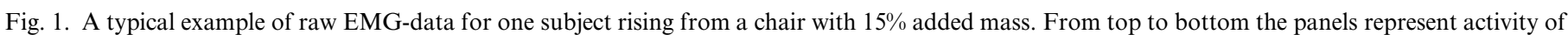

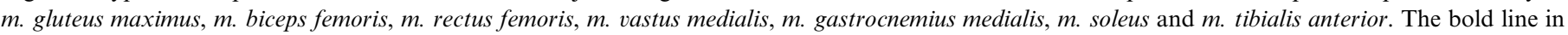

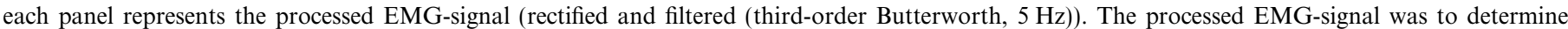

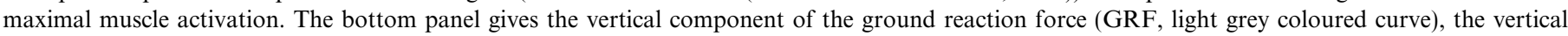

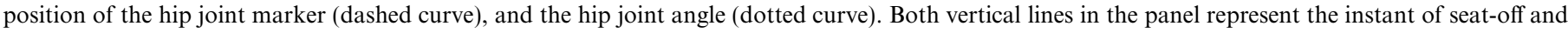
the end of the movement. These instants were based on respectively vertical displacement of the hip joint marker and the hip joint angle.

determined. The strategy change that we found does not occur gradually with increasing load, but it follows a bro- ken pattern, on the average when the load was increased from $30 \%$ to $45 \%$, the strategy change occurred. The 
Table 1

Strategy, net joint moment and muscle activation characteristics for four loading conditions

\begin{tabular}{|c|c|c|c|c|c|c|}
\hline & \multicolumn{4}{|c|}{ Conditions (mass added as percentage of body mass) } & \multirow[t]{2}{*}{$P$-value } & \multirow[t]{2}{*}{ Post hoc analysis } \\
\hline & $0 \%$ & $15 \%$ & $30 \%$ & $45 \%$ & & \\
\hline \multicolumn{7}{|l|}{ Strategy characteristics } \\
\hline Total movement time (ms) & $1766(274)$ & $1927(321)$ & $2028(322)$ & $2166(373)$ & 0.038 & $1<4$ \\
\hline Time to seat-off (ms) & $483(192)$ & $461(158)$ & $575(329)$ & $563(282)$ & 0.631 & \\
\hline Maximal trunk flexion angle (degrees) & $58.2(8.8)$ & $57.4(7.6)$ & $58.1(7.5)$ & $46.7(4.6)$ & $>0.001$ & $4<1=2=3$ \\
\hline \multicolumn{7}{|l|}{ Net joint moment characteristics } \\
\hline Maximum ankle plantar flexion moment (Nm) & $50.6(22.7)$ & $61.4(22.3)$ & $71.2(17.6)$ & $82.6(23.6)$ & 0.001 & $\begin{array}{l}1<2<3<4 \\
2=3,3=4\end{array}$ \\
\hline Maximum knee extension moment (Nm) & $113.3(26.0)$ & $134.7(27.0)$ & $145.0(33.1)$ & $174.6(51.6)$ & $<0.001$ & $1<2<3<4$ \\
\hline Maximum hip extension moment (Nm) & $110.4(23.4)$ & $104.8(20.8)$ & $126.5(30.7)$ & $148.4(16.5)$ & $<0.001$ & $1=2<3=4$ \\
\hline Time of maximum ankle plantar flexion moment $(\%)$ & $61.9(26.0)$ & $85.7(20.9)$ & $75.6(18.4)$ & $84.6(19.0)$ & 0.069 & \\
\hline Time of maximum knee extension moment $(\%)$ & $16.4(4.6)$ & $17.0(5.8)$ & $17.6(2.9)$ & $23.5(6.3)$ & 0.007 & $1=2=3<4$ \\
\hline Time of maximum hip extension moment (\%) & $11.1(4.3)$ & $12.6(3.8)$ & $13.5(4.0)$ & $13.8(4.5)$ & 0.120 & \\
\hline Relative contribution of ankle moment & $18.1(6.6)$ & $20.3(5.8)$ & $20.7(3.4)$ & $20.1(3.4)$ & $<0.001$ & $1<2=3=4$ \\
\hline Relative contribution of knee moment & $41.6(7.9)$ & $44.9(6.0)$ & $42.6(6.4)$ & $42.6(5.6)$ & $<0.001$ & $1<2>3=4$ \\
\hline Relative contribution of hip moment & $40.3(6.9)$ & $34.8(5.0)$ & $36.7(6.6)$ & $37.4(5.5)$ & $<0.001$ & $1>2<3=4$ \\
\hline \multicolumn{7}{|l|}{ Muscle activation characteristics } \\
\hline Gluteus maximus & 100 & $126.1(30.3)$ & $164.8(43.0)$ & $204.8(42.2)$ & $<0.001$ & $\begin{array}{l}1<2<3<4 \\
1=2,3=4\end{array}$ \\
\hline Biceps femoris & 100 & $116.8(43.1)$ & $121.9(31.5)$ & $165.7(58.1)$ & 0.001 & $1=2=3<4$ \\
\hline Rectus femoris & 100 & $142.4(59.3)$ & $159.6(60.9)$ & $196.6(69.8)$ & $<0.001$ & $1<2=3<4$ \\
\hline Vastus medialis & 100 & $117.9(28.1)$ & $132.2(23.2)$ & $155.3(27.8)$ & $<0.001$ & $1=2<3<4$ \\
\hline Gastrocnemius medialis & 100 & $108.4(29.7)$ & $126.8(43.1)$ & $143.3(67.9)$ & 0.043 & $2<4$ \\
\hline Soleus & 100 & $126.6(48.7)$ & $130.0(43.5)$ & $142.1(58.7)$ & 0.219 & \\
\hline Tibialis anterior & 100 & $113.5(17.8)$ & $119.5(37.6)$ & $122.1(32.1)$ & 0.122 & \\
\hline
\end{tabular}

Values represent means (standard deviations). 

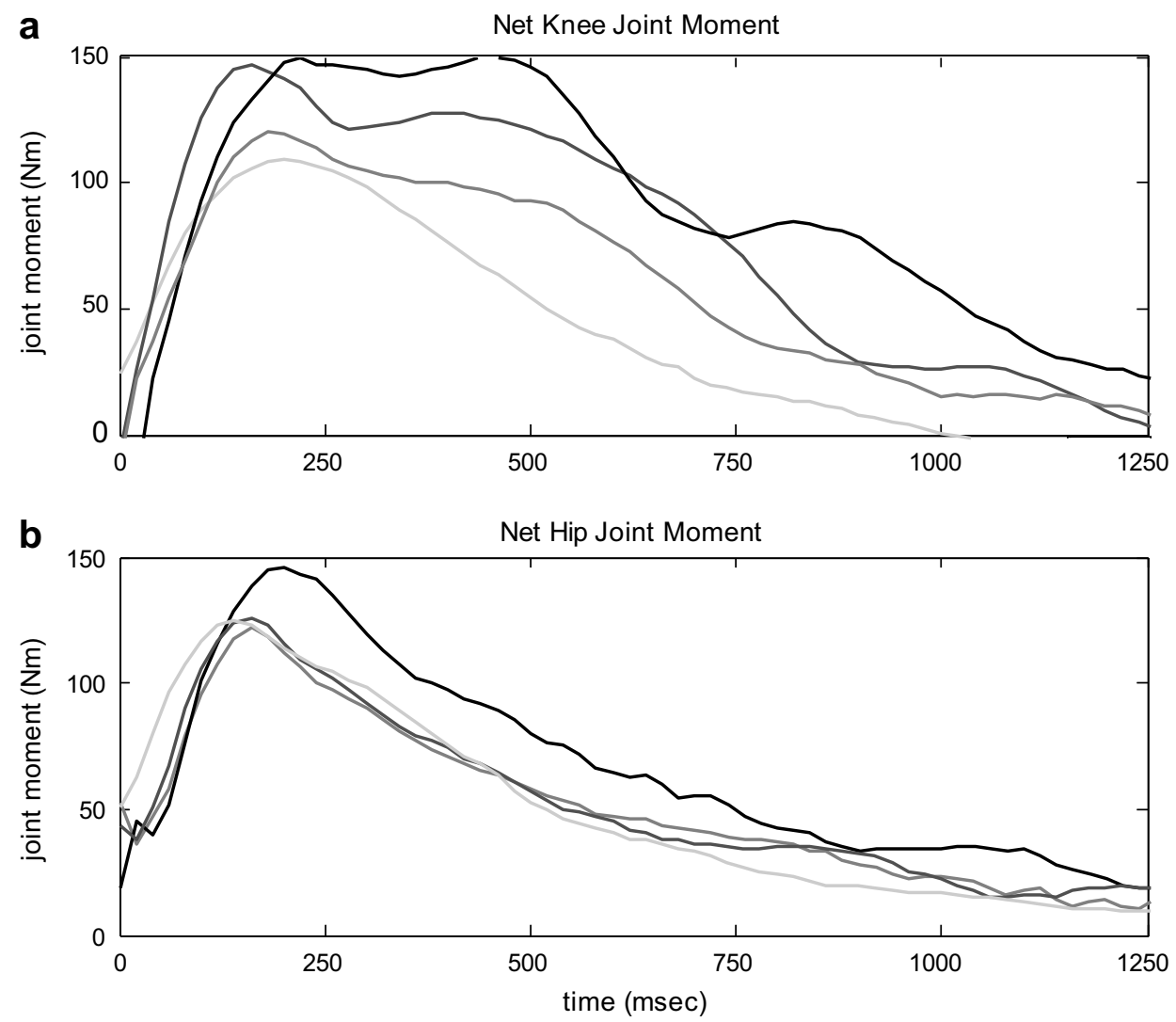

Fig. 2. Net joint moments for knee joint (upper panel) and hip joint (lower panel) for one subject under four conditions (colours of the curves change from light grey to black with increasing load capacity ratio). The time-scale starts with the instant of seat-off.

finding that an increased ratio induced a strategy change indicates that muscle weakness on its own, without any other age or disease related weakening can result in such a strategy change.

The strategy change can either be the result of the compromised force generating capacity of a specific muscle group, or be caused by factors associated to the load changes, i.e. compromised stability or affected confidence in balance control. If a specific muscle group is unable to provide the force required by the movement, the strategy change might result in a NJM pattern that enables other muscle groups to improve their contribution to the movement in order to spare the compromised muscle group. To understand how the strategy change is caused, the underlying NJMs and muscle activation patterns were assessed. Contrarily to the movement time and hip joint angle, the maximal ankle plantar flexion and knee extension NJMs showed a gradual increase. However the hip extension NJM displayed a discontinuous pattern (Fig. 2). For the timing of the NJMs, discontinuity was found for the instant that maximal knee extension NJM occurred; the timing of the hip extension NJM was not affected. Two suggestions arise from this pattern of NJM data. The first is that increasing knee extension and ankle plantar flexor NJM satisfies if the load/capacity ratio is increased without inducing a strategy change. Secondly, if a strategy change has been induced, the knee extension NJM has to be generated later and disproportionately larger hip extension NJM is required. In previous studies (Hughes et al., 1996; Moxley Scarborough et al., 1999) it has been suggested that especially weakness of knee extensors would induce an strategy change. At first glance the data of the present study would seem not to support this suggestion. Over the four conditions, the maximal knee extension NJM seemed to rise linearly with the load added (Fig. 2). So although a strategy change requires proportionally more hip extension NJM, that additional hip extension NJM does not seem to help the knee extension NJM to be reduced. However, we do not know the (net) knee joint moment that under the highest load condition would be required without a strategy change. It is possible that knee extension NJMs that have been generated in the highest load condition are close to the maximal isometric joint moment that subjects have available or to a certain threshold that triggers a strategy change. Based on the present data a definite answer to the question whether a specific muscle group becomes overloaded or reaches a threshold cannot be given. However, if any muscle group is overloaded, the knee joint extensors are likely to be a good candidate.

The muscle activation and NJM patterns indicated that the strategy change was associated with increased contribution of hip joint extensors, especially BF. Whereas the activ- 
ity of most other muscles increased gradually with load added, BF activity increased disproportionately between $30 \%$ and $45 \%$. Increasing the force generated by the $\mathrm{BF}$ would both contribute to increase the hip extension NJM and to counteract increase of the knee extension NJM. Also from the point of view of redistribution of joint moments, it can be understood that BF played an important role in the strategy change. Van Ingen Schenau et al. (1992) showed that through coactivation of monoarticular and biarticular (ant)agonists the distribution of NJMs over adjacent joints (e.g. the knee and the hip joint) can be controlled and that this is associated to the position and direction of the ground reaction force. A disproportional increase of the hip extension NJM relative to the knee extension NJM will result in a more forward position of the point of application of the ground reaction force. In this study the strategy change was related to a disproportional rise of the hip extension NJM. It can be understood that due to the increased trunk flexion the centre of gravity, that is the position of the ground reaction force, will be displaced forwardly. Also Sibella et al. (2003) reported in a study comparing the STS-performance of normal and obese subjects, a positive relation between increased hip extension NJM and increased trunk flexion. In conclusion, the above analysis suggests that knee extensors capacity sets limits to the moment transfer strategy and that additional hamstring activation is required to perform the stabilization strategy.

This study indicated that a considerable increase of the load/capacity ratio is required to invoke a strategy change; only in the $45 \%$ condition movement time was elongated and a significant effect on the hip joint angle was found. The subjects experienced the $45 \%$ condition as demanding. The less demanding conditions did not provoke the stabilization strategy. By adding $45 \%$ to the load, the ratio will increase by $45 \%$ too. A similar change of the ratio can be brought about by reducing muscle capacity with only $32 \%$. In a previous study we found strength reduction of knee extensors and flexors for elderly in their seventh decade to be $33 \%$ and $43 \%$, respectively (Savelberg and Meijer, 2004). Also other studies presented this magnitude of reductions in muscle function (Doherty, 2003; Macaluso et al., 2002). So from this point of view it is tempting to argue that the $45 \%$ added mass is representative for what elderly in their seventh decade experience daily. For people with diabetes muscle strength reductions of up to $17 \%$ relative to age-matched controls have been reported (Andersen et al., 2004). In addition to reduced muscle strength, elderly and chronic diseased are often confronted with increased BMI-values, so then not only the denominator of the ratio is negatively affected, in addition the numerator is increased. We estimate that the most severe increase of the load/capacity ratio in this study is not excessive at all for elderly and people with chronic diseases.

One might wonder whether influencing the load/capacity ratio by either increasing the numerator or decreasing the denominator makes a difference. As pointed out above, part of the problem is in fact the increase of body mass.
This occurs in elderly, in people with diabetes and is the intrinsic problem in obesity (Sibella et al., 2003). However, distribution of added mass over the body in this study differs from physiological distribution of weight gain or muscle strength reduction. Although the weight vest ensured a rather equal distribution of the added mass over the trunk, in reality added body mass is not restricted to the trunk. Moreover muscle weakness does not affect all muscles equally (Savelberg and Meijer, 2004). In addition, ageing is known to be associated to a relative increase of the amount of type I muscle fibres and grouping of motor units. Another point is that age-related changes and adaptations to chronic diseases will occur gradually, the effects induced by the experimental procedure are acute. In spite of these differences between reality and the model the changes in strategy that occur show that the model is at least able to bring about similar symptoms. Although in ageing and chronic disease other factors might be involved too, the present study demonstrated that decreased relative capacity of muscles affects STS-performance. In this study only women were included; to our knowledge there are no facts that would limit the transfer of the results to men.

In conclusion, this study resulted in an experimental model that can be used to study the isolated effect of the load/capacity ratio on STS-performance. The study showed that an isolated increase of the load/capacity ratio results in a strategy change. Based on the present data it cannot be concluded whether the force requested from a particular muscle group exceeds the available force or whether the load reaches such a level that stability or confidence in stability control is compromised. Whatever the cause, it was found that the strategy change is associated with redistribution of NJMs, but different than e.g. walking (Devita and Hortobagyi, 2000; Savelberg et al., 2007). The concept that was applied in this study, muscle weakness being represented by a load/capacity ratio, shows that improving performance might not only be obtained by increasing muscle strength, but might also be gained by lowering body mass. The nice thing of training is that it inherently affects both components in the right direction.

To be able to determine which of the muscles is the primary cause of the strategy change, a study forcing subjects to perform the momentum transfer strategy in the highest load condition would be necessary. Such a study would show how the knee extension NJM would behave under that condition and would allow conclusions with respect to the question whether knee joint extensor strength induces strategy change, or whether so far unknown conditions cause the strategy exchange.

\section{References}

Alexander, N.B., Schultz, A.B., Warwick, D.N., 1991. Rising from a chair: effects of age and functional ability on performance biomechanics. J. Gerontol. 46, M91-M98.

Andersen, H., Nielsen, S., Mogensen, C.E., Jakobsen, J., 2004. Muscle strength in type 2 diabetes. Diabetes 53, 1543-1548. 
Bernardi, M., Rosponi, A., Castellano, V., Rodio, A., Traballesi, M., Delussu, A.S., Marchetti, M., 2004. Determinants of sit-to-stand capability in the motor impaired elderly. J. Electromyogr. Kinesiol. 14, $401-410$.

Devita, P., Hortobagyi, T., 2000. Age causes a redistribution of joint torques and powers during gait. J. Appl. Physiol. 88, 1804-1811.

Doherty, T.J., 2003. Invited review: aging and sarcopenia. J. Appl. Physiol. 95, 1717-1727.

Doorenbosch, C.A.M., Harlaar, J., Roebroeck, M.E., Lankhorst, G.J., 1994. Two strategies of transferring from sit-to-stand; The activation of monoarticular and biarticular muscles. J. Biomech. 27, 1299-1307.

Eils, E., Behrens, S., Mers, O., Thorwesten, L., Volker, K., Rosenbaum, D., 2004. Reduced plantar sensation causes a cautious walking pattern. Gait Posture 20, 54-60.

Guralnik, J.M., Ferrucci, L., Simonsick, E.M., Salive, M.E., Wallace, R.B., 1995. Lower-extremity function in persons over the age of 70 years as a predictor of subsequent disability. New Engl. J. Med. 332, $556-562$.

Hughes, M.A., Myers, B.S., Schenkman, M.L., 1996. The role of strength in rising from a chair in the functionally impaired elderly. J. Biomech. 29, 1509-1513.

Hughes, M.A., Weiner, D.K., Schenkman, M.L., Long, R.M., Studenski, S.A., 1994. Chair rise strategies in the elderly. Clin. Biomech. 9, 187192.

Ikeda, E.R., Schenkman, M.L., Riley, P.O., Hodge, W.A., 1991. Influence of age on dynamics of rising from a chair. Phys. Ther. 71, 473-481.

Ingen Schenau, G.J.V., Boots, P.J.M., Groot, G.D., Schackers, R.J., Woensel, W.W.L.M.V., 1992. The constrained control of force and postion in multi-joint movements. Neuroscience 46, 197-207.

Janssen, W.G.M., Bussmann, H.B.J., Stam, H.J., 2002. Determinants of the sit-to-stand movement: a review. Phys. Ther. 82, 866-879.

Kaya, B.K., Krebs, D.E., Riley, P.O., 1998. Dynamic stability in elders: momentum control in locomotor ADL. J. Gerontol. A: Biol. Sci. Med. Sci. 53, M126-M134.
Kerr, K.M., White, J.A., Barr, D.A., Mollan, R.A.B., 1997. Analysis of the sit-stand-sit movement cycle in normal subjects. Clin. Biomech. (Bristol, Avon) 12, 236-245.

Macaluso, A., Nimmo, M.A., Foster, J.E., Cockburn, M., Mcmillan, N.C., Devito, G., 2002. Contractile muscle volume and agonistantagonist coactivation account for differences in torque between young and older women. Muscle Nerve 25, 858-863.

Meyer, P.F., Oddsson, L.I., De Luca, C.J., 2004. The role of plantar cutaneous sensation in unperturbed stance. Exp. Brain Res. 156, 505512.

Moxley Scarborough, D., Krebs, D.E., Harris, B.A., 1999. Quadriceps muscle strength and dynamic stability in elderly persons. Gait Posture $10,10-20$

Nurse, M.A., Nigg, B.M., 2001. The effect of changes in foot sensation on plantar pressure and muscle activity. Clin. Biomech. 16, 719-727.

Papa, E., Cappozzo, A., 2000. Sit-to-stand motor strategies investigated in able-bodied young and elderly subjects. J. Biomech. 33, 1113-1122.

Savelberg, H.H.C.M., Meijer, K., 2004. The effect of age and joint angle on the proportionality of extensor and flexor strength at the knee joint. J. Gerontol. A: Biol. Sci. Med. Sci. 59A, 1120-1128.

Savelberg, H.H.C.M., Verdijk, L.B., Willems, P.J.B., Meijer, K., 2007. The robustness of age-related gait adaptations; can running counterbalance the consequences of ageing? Gait Posture 25, 259-266.

Schenkman, M., Riley, P.O., Pieper, C., 1996. Sit-to-stand from progressively lower seat heights - alterations in angular velocity. Clin. Biomech. 11, 153-158.

Schultz, A.B., Alexander, N.B., Ashton-Miller, J.A., 1992. Biomechanical analyses of rising from a chair. J. Biomech. 25, 1383-1391.

Sibella, F., Galli, M., Romei, M., Montesano, A., Crivellini, M., 2003. Biomechanical analysis of sit-to-stand movement in normal and obese subjects. Clin. Biomech. 18, 745-750.

Winter, D.A., 1990. Biomechanics and Motor Control of Human Movement. John Wiley and Sons, New York. 